\title{
QUALIDADE FISIOLÓGICA DE SEMENTES DE GUABIJUZEIRO (Myrcianthes pungens (Berg) Legrand - MYRTACEAE) EM ARMAZENAMENTO1
}

\begin{abstract}
Claudimar Sidnei Fior ${ }^{2}$, Lia Rosane Rodrigues ${ }^{3}$, Anaíse Costa Calil ${ }^{2}$, Cristina Leonhardt ${ }^{2}$, Luana dos Santos de Souza ${ }^{4}$ e Vanessa Savian da Silva ${ }^{4}$

RESUMO - O guabijuzeiro ocorre no Brasil desde São Paulo até o Rio Grande do Sul. Suas sementes são de curta longevidade e intolerantes à dessecação. O objetivo deste trabalho foi avaliar a qualidade fisiológica de sementes de guabijuzeiro ao longo de oito meses de armazenamento em câmara fria $\left(5 \pm 1{ }^{\circ} \mathrm{C}\right.$ e $80 \%$ UR). Sementes de seis diferentes plantas localizadas os Municípios de Encruzilhada do Sul e Cachoeira do Sul, no Rio Grande do Sul, constituíram seis lotes, que foram avaliados quanto ao teor de água, à massa de mil sementes, à germinação, ao tempo médio de germinação em laboratório, à emergência e ao tempo médio de emergência em casa de vegetação. Até o terceiro mês de armazenamento, a viabilidade das sementes foi superior a 50\%, porém três lotes apresentaram valores acima de $75 \%$. Ao longo do período de armazenamento ocorreu pequena variação no teor de água (entre 40 e $45 \%$ ), e as sementes de todos os lotes perderam qualidade. Contudo, aos oito meses foram registradas viabilidades entre $56 \%$ e $61 \%$ em sementes de dois lotes, mostrando que, em ambiente de câmara fria, é possível prolongar a longevidade de sementes de guabijuzeiro.
\end{abstract}

Palavras-chave: Myrcianthes pungens, Sementes e Germinação.

\section{PHYSIOLOGICAL QUALITY OF GUABIJUZEIRO (Myrcianthes pungens (Berg) Legrand - MYRTACEAE) SEEDS UNDER STORAGE}

\begin{abstract}
Guabijuzeiro is a woody plant and occurs in Brazil, from the states of São Paulo until Rio Grande do Sul. Guabijuzeiro seeds are susceptible to dissection and present short longevity. The aim of this wotk was to evaluate the physiological quality of seeds throughout the course of eight months under cold chamber storage $\left(5 \pm 1{ }^{\circ} \mathrm{C}\right.$ and $80 \%$ RM). Seeds collected from six different plants, from Encruzilhada do Sul and Cachoeira do Sul districts in the state of Rio Grande do Sul, were evaluated in relation to moisture content, mass of 1000 seeds, germination, mean time to germination, emergence and mean time to emergence. Until the third month of storage, viability was higher than $50 \%$ and seeds from three progenies presented viability up to $75 \%$. Low variation in moisture content (40 to 45\%) was recorded during storage. The quality of the seeds from all origins decreased under storage, however after eight months, 56 to $61 \%$ of the seeds from two progenies remained viable. Thus, it is possible to extend longevity of guabijuzeiro seeds by means of cold chamber storage.
\end{abstract}

Keywords: Myrcianthes pungens, Seeds and Germination.

\section{INTRODUÇÃO}

Conhecido por guabijuzeiro, Myrcianthes pungens (Berg) Legrand é uma árvore perenifólia que atinge 15 a $25 \mathrm{~m}$ de altura (Figura 1.A), cujas folhas apresentam ápice espinescente muito característico. Ocorre no Brasil desde São Paulo até o Rio Grande do Sul, onde é encontrada em todas as formações florestais, com exceção da Floresta Atlântica e Restinga Litorânea. Sua floração ocorre nos meses de setembro a janeiro e a frutificação, de dezembro a abril. Os frutos, bagas globosas com polpa carnosa e comestível, são apreciados pela fauna nativa (MARCHIORI e SOBRAL, 1997; BACKES e IRGANG, 2002) e também pelos humanos.

\footnotetext{
${ }^{1}$ Recebido em 19.11.2007 e aceito para publicação em 02.03.2010.

${ }^{2}$ Fundação Zoobotânica do Rio Grande do Sul, FZB/RS, Brasil.Doutorando do Programa de Pós-graduação em Fitotecnia da UFRGS. E-mail: <csfior@fzb.rs.gov.br>.

${ }^{3}$ Fundação Estadual de Pesquisa Agropecuária, FEPAGRO, Brasil. E-mail: <liarr@ufrgs.br>

${ }^{4}$ Mestranda pela Universidade Federal do Rio Grande do Sul, UFRGS, Brasil. E-mail: <luanass1981@hotmail.com>e <vanessasavian@ibest.com.br>.
} 
A espécie é ornamental, utilizada na arborização urbana, embora ainda pouco cultivada para essa finalidade (SANCHOTENE, 1989; MARCHIORI e SOBRAL, 1997). Apresenta folhas de coloração verde-brilhante e copa densa com tronco tortuoso de superfície lisa.

Informações para subsidiar a produção de mudas desta espécie são escassas. Em viveiro, Sanchotene (1989) observou emergência de 50\% das sementes no período de 30 a 40 dias após a semeadura. Santos (2004) verificou elevado percentual de germinação de sementes (superior a $80 \%$ ) em condições de laboratório em diferentes temperaturas, identificando $25^{\circ} \mathrm{C}$ como a melhor condição para germinação.

Avaliando a tolerância à dessecação, Andrade (2002) classificou as sementes de guabijuzeiro como intolerantes. Essa característica ocorre em várias espécies de mirtáceas (GENTIL et al., 2004; ANDRADE, 2002; ANDRADE e FERREIRA, 2000; MALUF, et al., 2003; KOHAMA et al., 2006; DELGADO, 2006; BARBEDO et al., 1998). As sementes que apresentam essa característica possuem elevados teores de água por ocasião da maturação dos frutos, além de curta longevidade, mesmo em condições de elevada umidade relativa do ar e baixa temperatura. Esse período, entretanto, é variável entre espécies, uma vez que a intolerância à dessecação pode estar associada a vários compostos e processos, como o acúmulo de reservas insolúveis, a desdiferenciação celular, a presença de um eficiente sistema antioxidante, o acúmulo de proteínas e protetores de oligossacarídeos, além de outros açúcares, e a presença de um sistema de reparo eficiente durante a reidratação (PAMMENTER e BERJAK, 1999).

Uma das formas de manter o poder germinativo por períodos curtos de armazenagem de sementes recalcitrantes é armazenar em embalagens que mantenham o conteúdo de umidade original, sob temperaturas de $4{ }^{\circ} \mathrm{C}$ a $6{ }^{\circ} \mathrm{C}$ (CHIN, 1988). Assim, o presente trabalho teve como objetivo avaliar a qualidade fisiológica das sementes de guabijuzeiro durante o armazenamento nas condições de câmara fria, usualmente empregada para estender a longevidade de sementes sensíveis à dessecação.

\section{MATERIAL E MÉTODOS}

O trabalho foi conduzido no Laboratório de Sementes do Jardim Botânico da Fundação Zoobotânica do Rio Grande do Sul (JB/FZB), no período de fevereiro de 2005 a fevereiro de 2006.
Sementes foram colhidas de seis árvores localizadas nos municípios de Cachoeira do Sul (latitude: $30^{\circ} 02^{\prime}$, longitude: $52^{\circ} 53^{\prime}$, altitude de $72 \mathrm{~m}$ ) (lotes I, II e III) e Encruzilhada do Sul (latitude: $30^{\circ} 02^{\prime}$, longitude: $52^{\circ}$ 31', altitude de $427 \mathrm{~m}$ ) (lotes IV, V e VI), RS. O clima de ambas as regiões é classificado, segundo Köppen, como Cfa, com temperaturas médias anuais de $18,9^{\circ} \mathrm{C}$ e $17,3^{\circ} \mathrm{C}$, respectivamente, sendo a precipitação média de $1.500 \mathrm{~mm}$ anuais. As sementes que originaram os lotes I e II foram coletadas de duas plantas bastante semelhantes, tanto em dimensões das copas quanto em diâmetro dos troncos. Ambas vegetam sobre solos Litólicos eutróficos. Foram separadas em diferentes lotes por estarem distanciadas por cerca de $6 \mathrm{~km}$. A planta que originou o lote III é, aparentemente, mais jovem, pois apresenta copa e tronco bem menos expressivos. O solo desse local é um Podzólico VermelhoEscuro distrófico, com maior ação antrópica por situarse em região urbanizada. O lote IV foi colhido de uma planta de grande porte, principalmente copa ampla e ramos mais distribuídos em relação às demais. Os lotes V e VI foram coletados de plantas muito semelhantes, situadas lado a lado, em linha reta, formando uma alameda juntamente com mais cinco exemplares de idênticas características. Os locais onde vegetam as matrizes que originaram os lotes IV, V e VI apresentam solo Podzólico Vermelho-Amarelo distrófico.

De cada planta, foram coletados frutos com aspecto típico da fase de maturação (coloração roxo-escura do epicarpo), constituindo seis lotes (Figura 1 B).

As sementes foram despolpadas por maceração manual com o auxílio de uma peneira (Figura 1 C). Uma amostra foi tomada aleatoriamente de cada lote para avaliação da condição inicial do material. As demais sementes foram armazenadas em câmara fria a $5 \pm 1^{\circ} \mathrm{C}$ e $80 \%$ de umidade relativa do ar, acondicionadas em embalagens de polietileno e submetidas à avaliação mensal, do terceiro ao oitavo mês.

As amostras de sementes representativas de cada um dos lotes foram avaliadas por meio das seguintes determinações: a) teor de água (TA) - foi determinado pelo método da estufa a $105 \pm 3^{\circ} \mathrm{C}$, durante $24 \mathrm{~h}$, utilizandose duas repetições de 10 sementes, com 5 a 6 g cada (BRASIL, 1992). Os resultados foram expressos em percentagem; b) massa de mil sementes (M1000) - determinada segundo Brasil (1992), sendo os resultados expressos em gramas; c) germinação (G) conduzida com quatro amostras de 25 sementes, em 

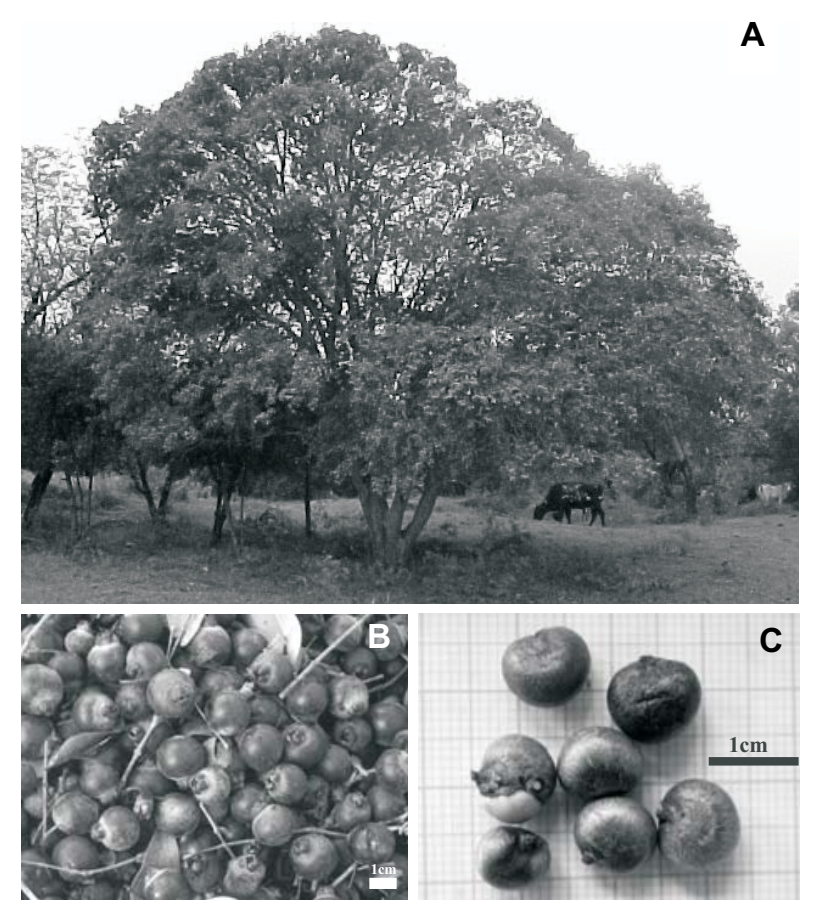

Figura 1-Myrcianthes pungens: A- Árvore matriz; B-Frutos; e C-Sementes.

Figure 1 - Myrcianthes pungens: A- Donor tree; B- Fruits; and $C$ - Seeds.

rolo de papel germiteste acondicionado em embalagem de polietileno transparente com fecho hermético, em germinador tipo Mangelsdorf, a $25^{\circ} \mathrm{C}$ e iluminação constante. As avaliações foram efetuadas a cada três ou quatro dias, durante 70 dias, considerando-se como critério de germinação a protrusão da raiz (2 mm); d) início da germinação (IG) - a partir do teste de germinação foi calculado o tempo decorrido entre a semeadura e a protrusão da raiz, expresso em dias; e) tempo médio de germinação (TMG) calculado conforme Silva e Nakagawa (1995), com base no número de sementes germinadas em cada avaliação multiplicado pelo respectivo tempo, dividido o resultado pelo número total de sementes germinadas ao final do teste; f) emergência de plântulas (E) conduzido com quatro subamostras de 25 sementes, estabelecidas em bandejas plásticas, contendo como substrato uma mistura de pó de coco (substrato comercial a base de fibra do mesocarpo de coco triturada) e areia, na proporção 2:1 (v/v). Após a semeadura, as bandejas foram mantidas em casa de vegetação, com 70\% de sombreamento e irrigação, conforme a necessidade. A avaliação da emergência das plântulas, identificada pela emergência do epicótilo, foi realizada a cada três e quatro dias até sua estabilização; g) início da emergência (IE) - calculado a partir do teste de emergência, é o tempo decorrido entre a semeadura e a emergência da alça do hipocótilo, expresso em dias; e h) tempo médio de emergência (TME) - calculado conforme Silva e Nakagawa (1995), através da fórmula do TMG, substituindo G por E.

O delineamento experimental foi inteiramente casualizado com seis tratamentos (lotes) e quatro repetições de 25 sementes. Os dados foram submetidos à análise de variância (ANOVA) e as médias, comparadas pelo teste de Tukey a 5\% de probabilidade. Para adequação à distribuição normal, dados das variáveis E e G foram transformados de acordo com Vieira (1999) (Tabela 1). Dados referentes à condição inicial do material foram submetidos à análise de correlação de Pearson. Os dados de germinação, emergência e tempo médio de germinação e emergência mensurados ao longo do período de armazenamento foram submetidos à análise de regressão polinomial.

\section{RESULTADOS E DISCUSSÃO}

Logo após a coleta, as sementes de todos os lotes apresentaram teores de água entre 41,4 e 43,6\%. Esses valores elevados no estádio de maturação são característicos de espécies recalcitrantes e estão de acordo com resultados encontrados por Andrade (2002), que classificou as sementes de $M$. pungens como intolerantes à dessecação.

Houve diferença significativa entre lotes em relação a todas as variáveis analisadas antes do armazenamento (Tabela 1). As sementes dos seis lotes apresentaram percentagem de germinação inicial acima de $80 \%$, destacando-se o lote VI, com 100\%. Em casa de vegetação, houve 66\% a 92\% de emergência, revelando diferença de vigor, com destaque para os lotes III, IV e V, com desempenho inferior.

A análise da variância não-paramétrica detectou diferença significativa entre lotes quanto ao início da germinação e emergência antes do armazenamento ( $\mathrm{P}<0,001$ e $\mathrm{P}=0,021$, respectivamente). $\mathrm{O}$ início da germinação aconteceu em média do oitavo ao décimo quinto dia após a semeadura. Vozzo (2002) mencionou que sementes de muitas espécies com elevado teor de água no ponto de maturação germinam rapidamente após a dispersão ou, ainda na planta matriz. 
Foi observada uma relação direta entre o tempo para início da emergência e o teor de água das sementes no ponto de coleta, confirmada pelo coeficiente de correlação significativo (Tabela 2). É possível que a maturação fisiológica da semente não esteja diretamente associada à maturação do fruto nem possa ser relacionada à coloração do epicarpo, pois, nas avaliações, foram extraídas sementes apenas de frutos considerados maduros.

O tempo médio de germinação variou de 17,6 a 30,1 dias em germinador e de 31,9 a 47 dias em casa de vegetação.

Houve diferença significativa entre lotes com relação à massa de mil sementes (M1000), variando de 184,8 g a 388, 2g, confirmando a variação de tamanho observada durante a despolpa dos frutos entre sementes de diferentes procedências. Sementes de maior M1000 não apresentaram melhor desempenho nos testes de germinação, pois o coeficiente de correlação foi negativo e significativo entre essa variável e o percentual de germinação, percentual, início e tempo médio de emergência (Tabela 2). Além disso, o lote VI, que teve M1000 inferior aos demais, apresentou 100\% de germinação inicial, superando significativamente o lote com maior M1000. Assim, os índices de germinação das sementes de guabijuzeiro não foram associados ao tamanho e, em consequência, às reservas. Tais observações divergem das proposições disponíveis na literatura. De acordo com Carvalho (2000), sendo determinação diretamente relacionada ao tamanho, a massa de mil sementes é representativa do vigor e, assim, influencia na germinação. Contudo, relação inversa entre massa ou tamanho e qualidade fisiológica de sementes também foi registrada anteriormente em outras espécies. Alves et al. (2005) mostraram que sementes de Mimosa caesalpiniifolia com maior M1000 apresentavam menor velocidade de germinação, estando esta diretamente relacionada com o vigor. Limas et al. (2007) registraram que sementes de Virola surinamensis de maior tamanho germinam mais lentamente em relação às menores.

Apesar de haver correlação significativa entre teor de água e IG, TME e IE, essa variável não se correlacionou com G, TMG e E. A ausência de correlação do teor de água com a viabilidade das sementes possivelmente indica equivalência de maturidade das sementes com este intervalo de umidade (41,4 e 43,6\%). Wielewicki et al. (2006) obtiveram teor médio de água de 39,6\% $\pm 4,8 \%$ ao analisarem lotes de sementes de guabijuzeiro para a proposição de padrões de teor de água e germinação.

De acordo com a análise de regressão $(\mathrm{P}<0,001)$, a porcentagem de germinação e emergência das sementes de todos os lotes corresponderam a linhas de tendência lineares decrescentes (Figuras 2 e 3) e os tempos médios de germinação e de emergência, a linhas de tendência lineares crescentes ao longo do armazenamento (Figuras 4 e 5). Somente as sementes do lote II apresentaram valores de tempo médio de emergência ajustáveis a uma equação de segundo grau.

Aos três meses de armazenamento, os três lotes de sementes com menor desempenho inicial (III, IV e V) já apresentavam redução significativa $(P>0,001)$ na

Tabela 1 - Características dos seis lotes de sementes de Myrcianthes pungens antes do armazenamento - teor de água (TA), massa de mil sementes (M1000), germinação, emergência, tempo médio de germinação (TMG) e tempo médio de emergência (TME).

Table 1 - Characteristics of six seed progenies from Myrcianthes pungens before storage - moisture content (TA), mass of 1000 seeds (M1000), germination, emergence, mean time to germination (TMG) and mean time to emergence (TME).

\begin{tabular}{|c|c|c|c|c|c|c|}
\hline Lotes & $\begin{array}{l}\text { TA } \\
(\%)\end{array}$ & $\begin{array}{l}\text { M1000 } \\
\text { (g) }\end{array}$ & $\begin{array}{c}\text { Germinação } \\
(\%)\end{array}$ & $\begin{array}{c}\text { Emergência } \\
\text { (\%) }\end{array}$ & $\begin{array}{l}\text { TMG } \\
\text { (dias) }\end{array}$ & $\begin{array}{l}\text { TME } \\
\text { (dias) }\end{array}$ \\
\hline I & 41,4 c & $311,2 \mathrm{~b}$ & $94 \mathrm{ab}$ & $89 \mathrm{ab}$ & 28,1 bc & $34,8 \mathrm{ab}$ \\
\hline II & 43,6 a & $218,3 \mathrm{~d}$ & $94 \mathrm{ab}$ & 92 a & $30,1 \mathrm{c}$ & $47,0 \mathrm{~d}$ \\
\hline III & 41,7 bc & 275,1 c & $82 \mathrm{~b}$ & 77 abc & 27,8 bc & 38,2 bc \\
\hline IV & 42,2 bc & 388,2 a & $84 b$ & 66 c & $19,3 \mathrm{ab}$ & 32,8 a \\
\hline V & $42,7 \mathrm{ab}$ & $184,8 \mathrm{e}$ & $93 \mathrm{ab}$ & 70 bc & 23,6 abc & 39,4 c \\
\hline VI & $41,4 \mathrm{c}$ & $226,0 \mathrm{~d}$ & 100 a & 91 a & 17,6 a & 31,9 a \\
\hline $\mathrm{P}>\mathrm{F}$ & 0,001 & $<0,001$ & 0,012 & 0,001 & 0,001 & $<0,001$ \\
\hline C.V. & 0,63 & 1,9 & 7,4 & 10,9 & 16,5 & 5,1 \\
\hline
\end{tabular}

Médias seguidas pela mesma letra na coluna não diferem entre si, pelo teste de Tukey (5\%).

Revista Árvore, Viçosa-MG, v.34, n.3, p.435-442, 2010 
Tabela 2 - Coeficientes de correlação de Pearson entre as variáveis mensuradas em sementes de Myrcianthes pungens ao longo de sete avaliações, antes do armazenamento e após três a oito meses em câmara fria. M1000: massa de mil sementes; TA: teor de água; G: germinação; TMG: tempo médio de germinação (dias); IG: início da germinação; E: emergência; TME: tempo médio de emergência (dias); e IE: início da emergência.

Table 2 - Pearson correlation coefficient among factors measured in Myrcianthes pungens seeds throughout the course of seven evaluations, before storage and at the third to eighth month under cold chamber storage. M1000: mass of 1000 seeds; TA: moisture content; G: germination; TMG: mean time to germination (days); IG: beginning of germination; TME: mean time to emergence (days); and IE: beginning of emergence.

\begin{tabular}{cccccccc}
\hline & TA & G & TMG & IG & E & TME & IE \\
\hline TA & - & $0,019 n s$ & $0,271 \mathrm{~ns}$ & $0,436^{*}$ & $-0,050 \mathrm{~ns}$ & $0,587^{*}$ & $0,736^{*}$ \\
M1000 & $-0,339 *$ & $-0,421^{*}$ & $-0,149 \mathrm{~ns}$ & $-0,164 \mathrm{~ns}$ & $-0,288^{*}$ & $-0,709^{*}$ & $-0,368^{*}$ \\
\hline
\end{tabular}

percentagem de germinação, enquanto os demais (lotes I, II e VI) mantiveram germinação igual ou superior a $80 \%$ até o quinto mês, destacando-se entre esses o lote II, que teve $87 \%$ de germinação no sexto mês de armazenamento. As curvas de regressão da germinação e da emergência (Figuras 2 e 3) ilustram as tendências em dois grupos, um formado pelos lotes I, II e VI e outro pelos lotes II, IV e V. Em relação ao tempo médio de germinação e emergência, a

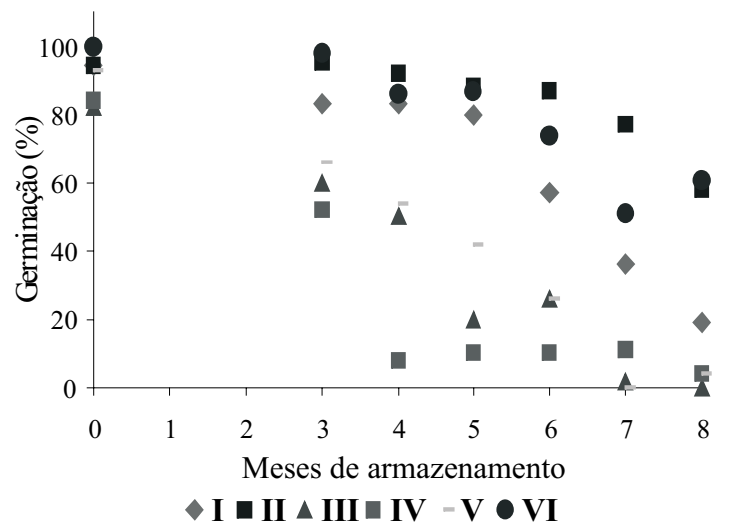

$$
\begin{array}{ll}
\text { I } & y=108,4-9,3 x \\
\text { II } & y=102,6-3,87 x \\
\text { III } & y=86,5-11,08 x \\
\text { IV } & y=72,9-10,06 x \\
\text { V } & y=98,41-12,24 x \\
\text { VI } & y=108,2-6,07 x
\end{array}
$$$$
\mathrm{R}^{2}=0,79
$$$$
\mathrm{R}^{2}=0,63
$$$$
\mathrm{R}^{2}=0,94
$$$$
\mathrm{R}^{2}=0,78
$$$$
\mathrm{R}^{2}=0,96
$$$$
\mathrm{R}^{2}=0,78
$$

Figura 2-Germinação de seis lotes de sementes de Myrcianthes pungens durante oito meses de armazenamento em câmara fria.

Figure 2-Germination of six seed progenies from Myrcianthes pungens throughout the course of eight months under cold chamber storage. tendência crescente (Figuras 4 e 5) aponta para a perda de vigor das sementes ao longo do armazenamento na maioria dos lotes já a partir do terceiro mês $(\mathrm{P}>0,001)$.

Ao final do período de armazenamento, no oitavo mês, somente três lotes (I, II e VI) mantiveram a viabilidade das sementes entre $40 \%$ e $58 \%$, enquanto as sementes dos demais perderam praticamente toda a viabilidade.

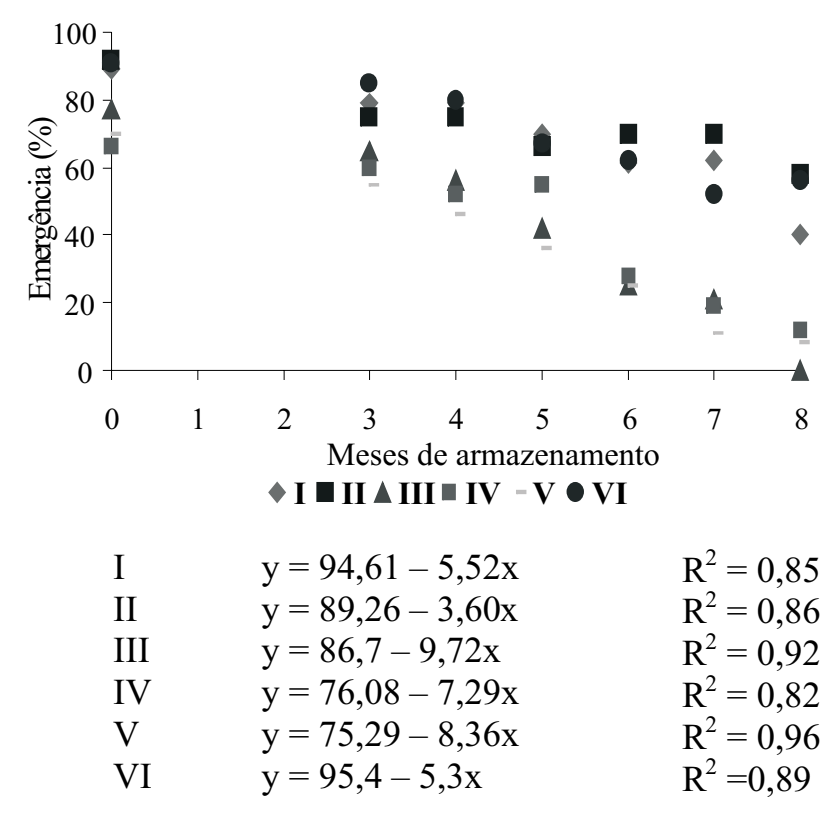

Figura 3-Emergência de seis lotes de sementes de Myrcianthes pungens durante oito meses de armazenamento em câmara fria.

Figure 3 - Emergence of six seed progenies from Myrcianthes pungens throughout the course of eight months under cold chamber storage.

Revista Árvore, Viçosa-MG, v.34, n.3, p.435-442, 2010 

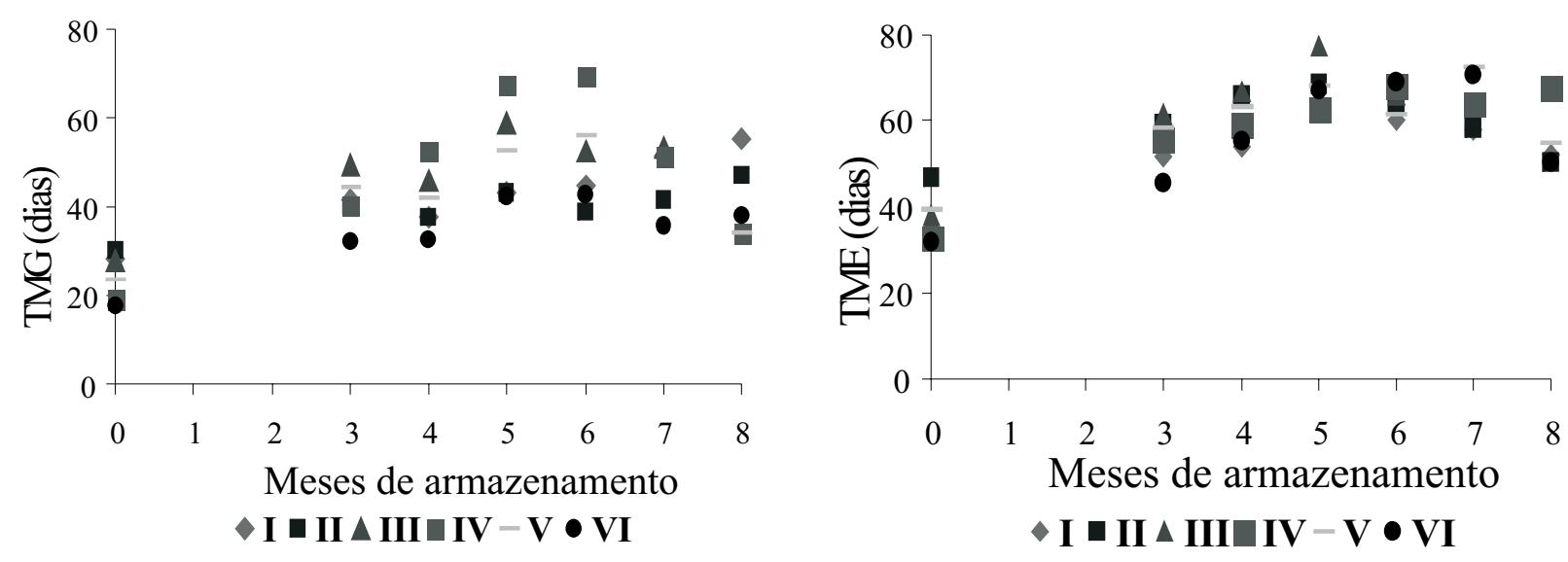

$$
\begin{array}{ll}
\text { I } & y=28,08+3,18 x \\
\text { II } & y=31,64+1,72 x \\
\text { III } & y=32,38+3,76 x \\
\text { IV } & y=32,58+3,23 x \\
\text { V } & y=33,05+2,09 x \\
\text { VI } & y=22,32+2,56 x
\end{array}
$$

$$
\begin{aligned}
\mathrm{R}^{2} & =0,92 \\
\mathrm{R}^{2} & =0,77 \\
\mathrm{R}^{2} & =0,74 \\
\mathrm{R}^{2} & =0,23 \\
\mathrm{R}^{2} & =0,23 \\
\mathrm{R}^{2} & =0,65
\end{aligned}
$$

$\begin{array}{ll}\text { I } & y=2,45 x+41,61 \\ \text { II } & y=-1,03 x 2+9,00 x+45,85 \\ \text { III } & y=3,98 x+45,54 \\ \text { IV } & y=4,18 x+38,86 \\ \text { V } & y=2,58 x+47,51 \\ \text { VI } & y=3,83 x+37,60\end{array}$

$\mathrm{R}^{2}=0,53$

$\mathrm{R}^{2}=0,90$

$\mathrm{R}^{2}=0,58$

$\mathrm{R}^{2}=0,85$

$\mathrm{R}^{2}=0,42$

$\mathrm{R}^{2}=0,51$

Figura 4 - Tempo médio de germinação de seis lotes de sementes de Myrcianthes pungens durante oito meses de armazenamento em câmara fria.

Figure 4 - Mean time to germination of six seed progenies from Myrcianthes pungens throughout the course of eight months under cold chamber storage.

Neste trabalho, o teste de emergência em condições não controladas contribuiu para identificar diferenças de qualidade entre os lotes de sementes não detectadas pelo teste inicial de germinação. Assim, foram identificados os lotes com maior potencial de armazenamento. Como afirmaram Roberts e Ellis (1984), mesmo em uma amostra de sementes geneticamente uniformes, armazenada em condições estáveis de ambiente, há variação considerável na longevidade. As diferenças nas respostas de sementes de diferentes lotes têm múltiplas causas, incluindo as variações ambientais de cada local de coleta, a variabilidade genética da planta matriz e a segregação genética entre indivíduos de cada progênie, que causa variações em todas as respostas fenotípicas, inclusive na germinação e emergência.

A diferença apontada pela massa de mil sementes também foi visualizada, mas não mensurada, no tamanho dos frutos. Contudo, foi identificado um baixo valor de correlação entre a percentagem de germinação e emergência inicial, além do fato de os valores mais elevados de massa não coincidirem com os dos lotes que permaneceram viáveis ao final do armazenamento.

A resposta das sementes aos testes de germinação indicou que $M$. pungens é uma espécie alógama, dada a diferença entre lotes nas respostas obtidas nos testes. Essa suposição é reforçada quando analisados isoladamente os dados dos lotes V e VI. Embora totalmente discrepantes, trata-se de sementes obtidas de matrizes dispostas lado a lado, formando uma alameda juntamente com outros exemplares, o que indica que estes tenham sido estabelecidos na mesma época, podendo, inclusive, ter origem de uma mesma matriz. Pelos altos índices de heterozigose, característicos das espécies alógamas (ENGELS et al., 2000), a variação das respostas das sementes de guabijuzeiro, antes do armazenamento e durante, é resultante da segregação de genes envolvidos na formação do embrião e da semente e, também, no desempenho fisiológico durante a germinação e a emergência. 


\section{CONCLUSÃO}

Sementes de guabijuzeiro coletadas com elevada qualidade inicial e armazenadas em condições de câmara fria podem ter sua longevidade estendida por cerca de oito meses.

\section{REFERÊNCIAS}

ALVES, E. U. et al. Influência do tamanho e da procedência de sementes de Mimosa caesalpinifolia Benth. sobre a germinação e vigor. Revista Árvore, v.29, n.6, p.877-885, 2005.

ANDRADE, R. N. B. Germinação de sementes de plantas ornamentais ocorrentes no Rio Grande do Sul. 2002.110f. Teses (Doutorado em Ciências) Instituto de Biociências Universidade Federal do Rio Grande do Sul, Porto Alegre, 2002.

BACKES, P.; IRGANG, B. Árvores do Sul; guia de identificação \& interesse ecológico - as principais espécies nativas sul-brasileiras. Santa Cruz do Sul: Clube da Árvore/Instituto Souza Cruz, 2002. 325p.

BARBEDO, C. J. et al. Germinação e armazenamento de diásporos de cerejeira (Eugenia involucrata DC. - MYRTACEAE) em função do teor de água. Revista Brasileira de Sementes, v.20, n.1, p.184-188, 1998.

BRASIL. Ministério da Agricultura e Reforma Agrária. Regras para análise de sementes. Brasília: SNDA/DNDV/CLAV, 1992. 365p.

CARVALHO, N. M.; NAKAGAWA, J. Sementes: ciência, tecnologia e produção. Campinas: Fundação Cargill, 2000. 588p.

CHIN, H. F. Recalcitrant seeds: a status report. Roma: IBPGRI, 1988. 28p.

FERREIRA, A. G.; BORGHETTI, F. Germinação: do básico ao aplicado. Porto Alegre: Artmed, 2004. 323p.

DELGADO, F. D. Tolerância à dessecação em sementes de espécies brasileiras de Eugenia. 2006. 106f. Dissertação (Mestre em Biodiversidade Vegetal e Meio Ambiente) Instituto de Botânica - Jardim Botânico. Secretaria do Meio Ambiente, São Paulo, 2006.
ENGELS, J. M. M. et al. Managing plant genetic diversity. Oxfordshire: CABI Publishing, 2000. 514p.

GENTIL, D. F. O.; SILVA, W. R.; FERREIRA, S. A. N. Conservação de sementes de Myrciaria dubia (H.B.K.) McVaugh. Bragantia, v.63, n.3, p.421-430, 2004.

KOHAMA, S. et al. Secagem e armazenamento de sementes de Eugenia brasiliensis Lam. (grumixameira). Revista Brasileira de Sementes, v.28, n.1, p.72-78, 2006.

LIMAS, D. L.; SILVA, B. M. S.; MORAES, W. S. Germinação e armazenamento de sementes de Virola surinamensis (Rol.) Warb.

(Myristicaceae). Revista Árvore, v.31, n.1, p.37-42, 2007.

MALUF, A. M.; BILIA, D. A. C.; BARBEDO, C. J. Drying and storage of Eugenia involucrata DC. seeds. Scientia Agricola, v.60, n.3, p.471-475, 2003.

MARCHIORI, J. N. C.; SOBRAL, M.

Dendrologia das angiospermas: Myrtales. Santa Maria: Universidade Federal de Santa Maria, 1997. 304p.

PAMMENTER, N. W.; BERJAK, P. A review of recalcitrant seed physiology in relation to desiccation-tolerance mechanisms. Seed Science Research, v. 9, p. 13-37, 1999.

PIÑA-RODRIGUES, F. C. M.;AGUIAR, I. B. Maturação e dispersão de sementes. In: AGUIAR, I. B.; PINÃ-RODRIGUES, F. C. M.; FIGLIOLIA, M. B. Sementes florestais tropicais. Brasília: ABRATES, 1993. p.215-274.

SANCHOTENE, M. C. C. Frutíferas nativas úteis à fauna na arborização urbana. Porto Alegre: Feplam, 1989.309p.

ROBERTS, E. H.; ELLIS, R. H. The implication of the deterioration of orthodox seeds during storage for genetic resources conservation. In: HOLDEN, J.H.W.; WILLIAMS, J.T., (Eds.) Crop genetic resources conservation and evaluation. London: IBPGR, 1984. p.42-53. 
SANTOS, C. M. R.; FERREIRA, A. G.; ÁQUILA, M. E. A. Características de frutos e germinação de sementes de seis espécies de Myrtaceae nativas do Rio Grande do Sul. Ciência Florestal, v. 14, n. 2, p. 13-20, 2004.

SILVA, J. B. C.; NAKAGAWA, J. Estudos de fórmulas para cálculo de germinação.

Informativo ABRATES, v. 5, n. 1, p. 6273, 1995.
VIEIRA, S.. Estatística experimental. São Paulo: Atlas, 1999. 185p.

VOZZO, J.A. Tropical tree seed manual. Washington: U.S. Department of Agriculture, Forest Service, Southern Research Station, 2002. 899p.

WIELEWICKI, A. P. et al. Proposta de padrões de germinação e teor de água para sementes de algumas espécies florestais presentes na região sul do Brasil. Revista Brasileira de Sementes, v.28, n.3, p.191-197, 2006. 